\title{
British medical schools fear funding changes
}

British medical schools are nervously awaiting the full impact of wide-ranging reforms in the way that research is supported through the National Health Service. The reforms are being introduced by Virginia Bottomley, the Secretary of State for Health. Although welcoming the reforms in principle, the medical schools fear they could erode both overall levels of support for research, and the degree of control that the medical schools now exercise over research projects.

Shortly before Christmas, Bottomley was expected to announce details of one of the main planks of the reform, a new national committee that will directly oversee the distribution of the almost $£ 437$ million that the NHS spends every year on health-related research.

There has been widespread support for one of the main changes, namely the decision that health-related research should be funded through a levy on the money that the government gives to health purchasers, such as local health authorities. This was a central recommendation of the report on which the reforms are based, prepared by a committee headed by Anthony Culyer, professor of medical economics at the University of York.

There has also been general enthusiasm for another key principle behind Culyer's recommendations, namely that all NHSfunded research should be assessed for its scientific quality and/or clinical relevance before support is agreed. At present, a substantial amount of money - no one knows exactly how much - is spent on research whose academic and clinical value is not closely assessed.

But medical schools are also worried that the changes could mean a net reduction in government funding, which, coming on top of other budget cuts, could lead some into substantial financial problems. "Our main concern is that the economic base of the teaching hospitals might be threatened by having a major resource withdrawn and then not totally reinjected," says Sir Colin Dollery, dean of the Royal Hammersmith Postgraduate Medical College in London.

Two factors lie behind the new reforms, the culmination of extensive discussions over the past few years. One is the need to ensure a secure basis for long-term research within the new 'internal market' that the Conservative government introduced in the 1980 s into the health service.

\section{LONDON}

Under this system, most decisions on resources now result from a negotiation between a 'purchaser' of health-care (which can be a general practitioner, or a health authority) and a 'provider' (such as a doctor or a hospital). This shift is intended primarily to increase the efficiency with which funds are spent. But even the Conservative government has now recognized the danger, highlighted in the Culyer Report, that neither side may have an immediate interest in funding long-term research.

The second factor lies in the government's more general concern that researchers and research groups should be made more accountable as to how the money is spent. Central to this is its decision to disaggregate the $£ 490$ million a year currently provided to teaching hospitals as the so-called Service Increment for Teaching and Research (SIFTR).

At present, the size of SIFTR allocations, intended primarily to cover the 'service' costs of research, such as buildings and extra staff, are calculated on clinical student numbers. In future - in a move which echoes similar reforms already introduced into the funding of universities - the size of the ' $R$ ' element of SIFTR will be based on a separate evaluation of the research potential of the teaching hospital in question.

Some have welcomed the new procedures as a way of ensuring that limited research funds within the health service are targeted on individuals and groups who are likely to use them most effectively. "I do not see why the money should be used to back up inefficient departments in a teaching hospital on the basis of what the dean and the chief executive officer decide between them," says Roger Williams director of the Institute of Liver Research at Kings College Medical and Dental School in London.

The biomedical research community has warmly endorsed the Culyer's report's support of the latter point of view. David Evered, the deputy chief executive of the Medical Research Council, argues that some so-called research carried out in teaching hospitals does not really deserve such a label. "There is a lot of rather loose additional investigations [being called research]," he says. "If that is squeezed out of the system, none of us will be any the poorer."

University medical school officials say that they, too, are supportive of the general principle. Sir Keith Peters, professor of physic [sic] at Cambridge University, has claimed that the Culyer proposal "provides a vital incentive for [health-service managers] to realize that research is their business."

But at the same time, the medical schools are wary of what it will mean in practice. "Our main concern is the danger of leakage'" says Sir Michael Thompson, vicechancellor of Birmingham University and chairman of the Committee of Vice Chancellors and Principals. "We are only barely able to operate effectively with what we have at present. If that money was to be allocated to other purposes, I feel that we could not carry out those functions which we are required to fulfil."

The universities have already reacted coolly to an announcement last November by Bottomley that the SIFTR allocation was to be increased from $£ 490$ million to $£ 530$ million by shifting an additional $£ 40$ million from funds allocated to health-care purchasers to those provided directly to the medical schools.

Bottomley described the money, which by her action will now be set aside for the support of teaching and research, as an indication of the government's commitment to "supporting the NHS' national and international reputation for research". But university officials say that unpublished estimates by Health Department officials indicate that the real extra costs of teaching and research may be as much as $£ 135$ million higher than the current SIFTR allowance.

The key issue still under debate is the extent to which the new arrangements will shift control of research funds in medical schools away from the schools themselves and into the hands of health-service administrators.

The government is arguing that such a shift is necessary to increase the efficiency with which health-related research funds are used. But the university medical schools claim that excessive centralization could undermine their effectiveness - and that it is therefore important that they continue to have a strong voice in decisions at both a national and regional level.

Dollery explained the dilemma clearly to a House of Lords committee in November. "We do not want to act in isolation from the strategy of the health service," he says. "But neither do we want to be totally bound by this strategy."

DAVID DICKSON News editor, Nature 